\title{
Synthesis of a water-soluble 2,2'-biphen[4]arene and its efficient complexation and sensitive fluorescence enhancement towards palmatine and berberine
}

\author{
Xiayang Huang ${ }^{1,2}$, Xinghua Zhang ${ }^{*}$, Tianxin Qian², Junwei $\mathrm{Ma}^{2}$, Lei Cui ${ }^{2}$ \\ and Chunju Li ${ }^{*} 1,2$
}

\author{
Full Research Paper \\ Address: \\ ${ }^{1}$ School of Chemical and Environmental Engineering, Shanghai \\ Institute of Technology, 100 Hai-Quan Road, Shanghai 201418, \\ P. R. China and ${ }^{2}$ Department of Chemistry, Center for \\ Supramolecular Chemistry and Catalysis, Shanghai University, \\ Shanghai 200444, P. R. China \\ Email: \\ Xinghua Zhang ${ }^{*}$ - xhzhang@sit.edu.cn; Chunju Li ${ }^{*}$ - cjli@shu.edu.cn \\ * Corresponding author \\ Keywords: \\ berberine; biphenarenes; host-guest complexes; molecular \\ recognition; palmatine
}

Beilstein J. Org. Chem. 2018, 14, 2236-2241.
doi:10.3762/bjoc.14.198
Received: 01 May 2018
Accepted: 15 August 2018
Published: 27 August 2018
This article is part of the thematic issue "Macrocyclic and supramolecular
chemistry".
Guest Editor: M.-X. Wang
C 2018 Huang et al.; licensee Beilstein-Institut.
License and terms: see end of document.

\begin{abstract}
A water-soluble $2,2^{\prime}$-biphen[4]arene (2,2'-CBP4) containing eight carboxylato moieties was synthesized and characterized. Its complexation behavior towards two alkaloids, palmatine (P) and berberine (B), was investigated by means of fluorescence and ${ }^{1} \mathrm{H}$ NMR spectroscopy in aqueous phosphate buffer solution (pH 7.4). In the presence of $2,2{ }^{\prime}-\mathrm{CBP} 4,{ }^{1} \mathrm{H}$ NMR signals of $\mathbf{P}$ and $\mathbf{B}$ displayed very large upfield shifts, indicating the formation of inclusion complexes with strong binding affinities. Fluorescence titration experiments showed that $\mathbf{P}$ and $\mathbf{B}$ exhibited dramatic fluorescence enhancement of more than 600 times upon complexation with $2,2^{\prime}$-CBP4. Particularly, the fluorescence intensity is strong enough to be readily distinguished by the naked eye. Although the two guests have similar structures, the association constant of $\mathbf{B}$ with $2,2^{\prime}-\mathrm{CBP} 4\left(K_{\mathrm{a}}=(2.29 \pm 0.27) \times 10^{6} \mathrm{M}^{-1}\right)$ is 3.9 times larger than that of $\mathbf{P}\left(K_{\mathrm{a}}=(5.87 \pm 0.24) \times 10^{5} \mathrm{M}^{-1}\right)$.
\end{abstract}

\section{Introduction}

Host-guest chemistry in water is significantly important due to its extensive applications in biology, medicine, and environment. Cyclodextrins [1-4], cucurbiturils [5-11], and calixarenes [12-20] have been widely used in aqueous supramolecular chemistry. In the past ten years, the chemistry of pillar[ $n]$ arenes has developed very quickly because of their specific structures and interesting host-guest properties [21-32]. Water-soluble pillar $[n]$ arene derivatives, especially those containing carboxyl- 
ato moieties, showed low cell toxicity and good biocompatibility, and have been applied in biomedical applications such as bioimaging and self-assembled drug delivery systems [33-40]. For example, our group demonstrated a direct host-guest complexation-based drug delivery system for oxaliplatin by carboxylatopillar[6]arene [36]. The encapsulation could not only improve the drug's stability in the blood stream, but also be effectively dis-assembled in the acidic tumor environment, and thus improve the anticancer activity of oxaliplatin in vivo.

In 2015, we introduced a new class of macrocyclic arenes, 4,4'biphen $[n]$ arenes $(n=3,4)$ with 4,4 '-biphenol or 4,4'-biphenol ether monomers linked by $-\mathrm{CH}_{2}-$ bridges [41], which have received much attention due to their convenient synthesis and modification method, novel topological structures and excellent cavity host-guest properties [41-46]. In 2017, another type of biphen $[n]$ arenes with 2,2'-disubstituted biphenyl units, 2,2'biphen $[n]$ arenes $(n=4-8)$, have been designed and synthesized [47].

To date, the complexation of biological and pharmaceutical molecules by biphen $[n]$ arenes in water have not been reported.
In this work, we wish to report the synthesis of the first watersoluble 2,2'-biphen[4] arene bearing multiple carboxylato moieties, 2,2'-CBP4 (Scheme 1), and its binding behavior and fluorescent spectrum characteristic towards two alkaoilds, palmatine (P) and berberine (B), in water solution. In particular, the fluorescence intensities of the two guests have been considerably enhanced after complexation. As a member of isoquinoline alkaloids' family, $\mathbf{P}$ and $\mathbf{B}$ can produce singlet oxygen $\left({ }^{1} \mathrm{O}_{2}\right)$ and oxide biological substrates under light, and thereby have applications in photodynamic therapy (PDT) [48-50]. However, their low quantum yields limit such applications, which could be potentially improved or restored by the present encapsulation-induced fluorescence enhancement.

\section{Results and Discussion Synthesis}

Scheme 1 shows the synthetic route of 2,2'-CBP4 [51], which is very similar with the procedure of water-soluble $4,4^{\prime}$ biphenarene [46]. Perhydroxylated 2,2'-biphen[4]arene, (2,2'OHBP4) with hydroxy reaction sites was quantitatively prepared by the deprotection of 2,2'-OEtBP4 using excess $\mathrm{BBr}_{3}$. The nucleophilic substitution reaction of 2,2'-OHBP4 and ethyl

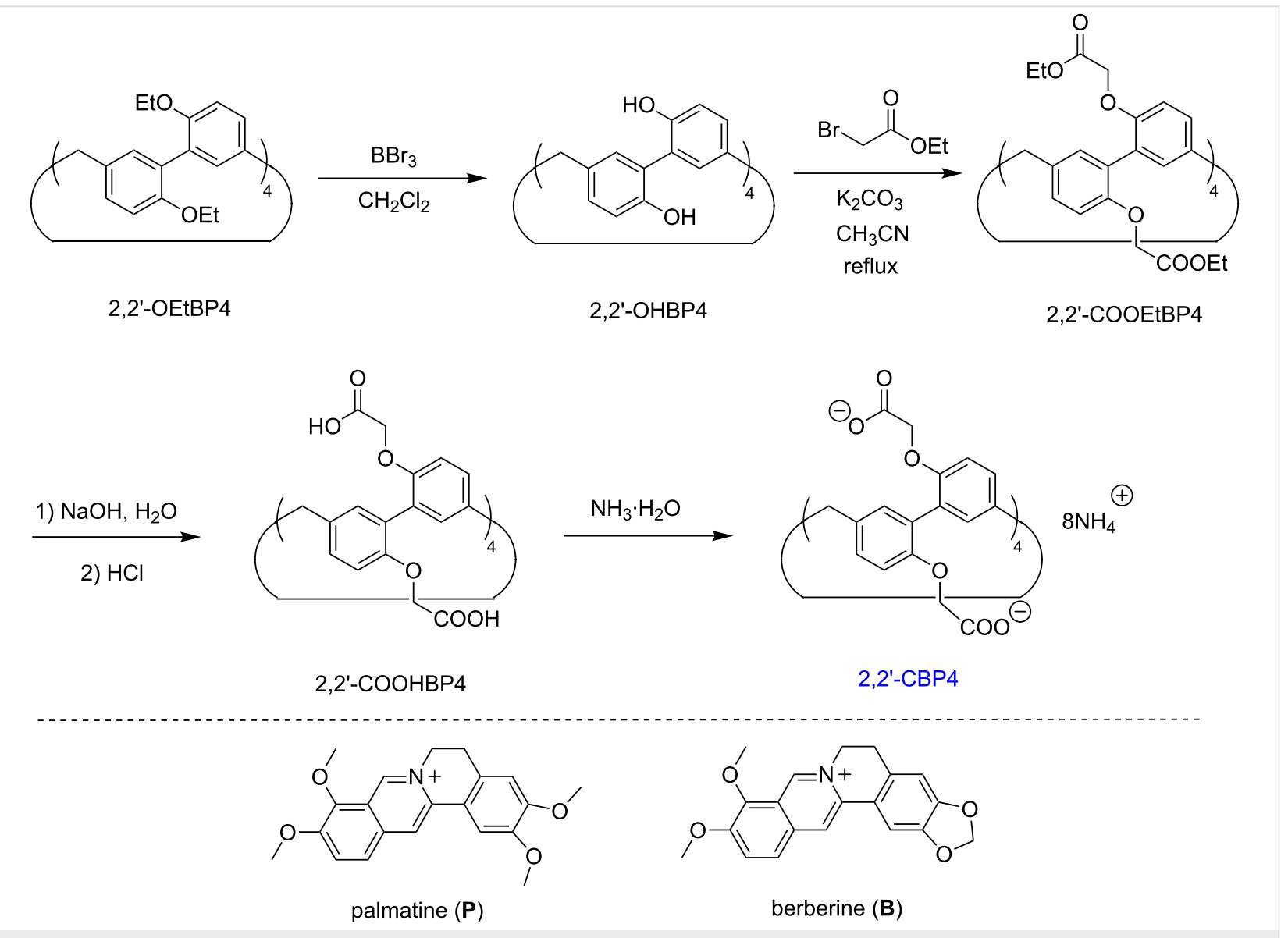

Scheme 1: Synthesis of 2,2'-CBP4 and the chemical structures of $\mathbf{P}$ and $\mathbf{B}$. 
bromoacetate, $\mathrm{K}_{2} \mathrm{CO}_{3}$ as the base, afforded 2,2'-COOEtBP4 in $88 \%$ yield. The hydrolysis of 2,2 '-COOEtBP4 in $\mathrm{NaOH}$ solution and then acidification with $\mathrm{HCl}$ yielded 2,2'-COOHBP4 in a high yield of $87 \%$. Water soluble 2,2'-CBP4 was quantitavely prepared by the acid-base reaction of 2,2'-COOHBP4 and aqueous ammonia solution. The total yield is up to $77 \%$. As expected, 2,2'-CBP4 has a very good solubility $(\geq 10 \mathrm{mM})$ in water.

\section{${ }^{1} \mathrm{H}$ NMR spectra}

${ }^{1} \mathrm{H}$ NMR experiments of $\mathbf{P}$ and $\mathbf{B}$ with 2,2'-CBP4 in deuterated phosphate buffer ( $\mathrm{pD} 7.4$ ) were carried out to examine the host-guest complexation (Figure 1 and Figure S9 in Supporting Information File 1). From Figure 1, upon addition of the host, all the peaks of alkaloid $\mathbf{B}$ displayed upfield shifts and broadening compared with the free guest. Especially, the chemical shifts for the middle protons, H1-6, and H10-11, are larger than those for the ending H7-9. These results indicate that berberine was engulfed by the cavity of 2,2'-CBP4 to form a pseudorotaxane-type inclusion complex. Similar complexation-induced NMR changes were observed for the host-guest mixture of $\mathbf{P}$ and 2,2'-CBP4 (Supporting Information File 1, Figure S9), suggesting a similar binding mode of an inclusion complex.

The host-guest encapsulation was then confirmed by 2D NOESY experiments, as shown in Figures S10 and S11, Supporting Information File 1. For example, in the 2D NOESY spectra of host-guest mixture of 2,2'-CBP4 and B, NOE correlations were clearly observed between the middle protons $\mathrm{H} 1$ and $\mathrm{H} 10$ of $\mathbf{B}$ with the methylene $\mathrm{H}_{\mathrm{c}}$ of 2,2'-CBP4, and between the aromatic protons $\left(\mathrm{H}_{\mathrm{b}}\right)$ of $2,2^{\prime}-\mathrm{CBP} 4$ and $\mathrm{H} 2$ of $\mathbf{B}$ (Supporting Information File 1, Figure S11).

To examine the fluorecence behavior and to quantitatively assess the complexation of the two alkaloids and 2,2'-CBP4, spectral titrations of $\mathbf{P} / \mathbf{B}$ and 2,2'-CBP4 were performed in the phosphate buffer solution of $\mathrm{pH} 7.4$ at $298 \mathrm{~K}$. As can be seen from Figure 2 and Supporting Information File 1, Figure S10, compounds $\mathbf{P}$ and $\mathbf{B}$ alone only displayed fairly feeble fluorescence emission. Upon addition of 2,2'-CBP4, the fluorescence intensity was remarkably improved more than 600 times (Figure 2 and Supporting Information File 1, Figure S10). This was due to the effect of lowering polar microenvironment when $\mathbf{P}$ or $\mathbf{B}$ was included by 2,2'-CBP4; the guest emits stronger fluorescence in a more hydrophobic microenvironment [48]. Combined with NMR results, we can unambiguously conclude the alkaloid molecules must insert into the hydrophobic cavity of $2,2^{\prime}$-CBP4 to form inclusion complexes. Interestingly, the emission intensities can be easily identified by the naked eye under UV light of $365 \mathrm{~nm}$. As can be seen from Figure 3, P, B and 2,2'-CBP4 alone are almost nonfluorescent; the host-guest mixture shows very strong yellow fluorescence.

Through analyzing the sequential changes about fluorescence intensity $(\Delta F)$ of guest that occurred with changes in host concentration, the association constants $\left(K_{\mathrm{a}}\right)$ could be calculated. The complexation stoichiometry for each binding event was de-

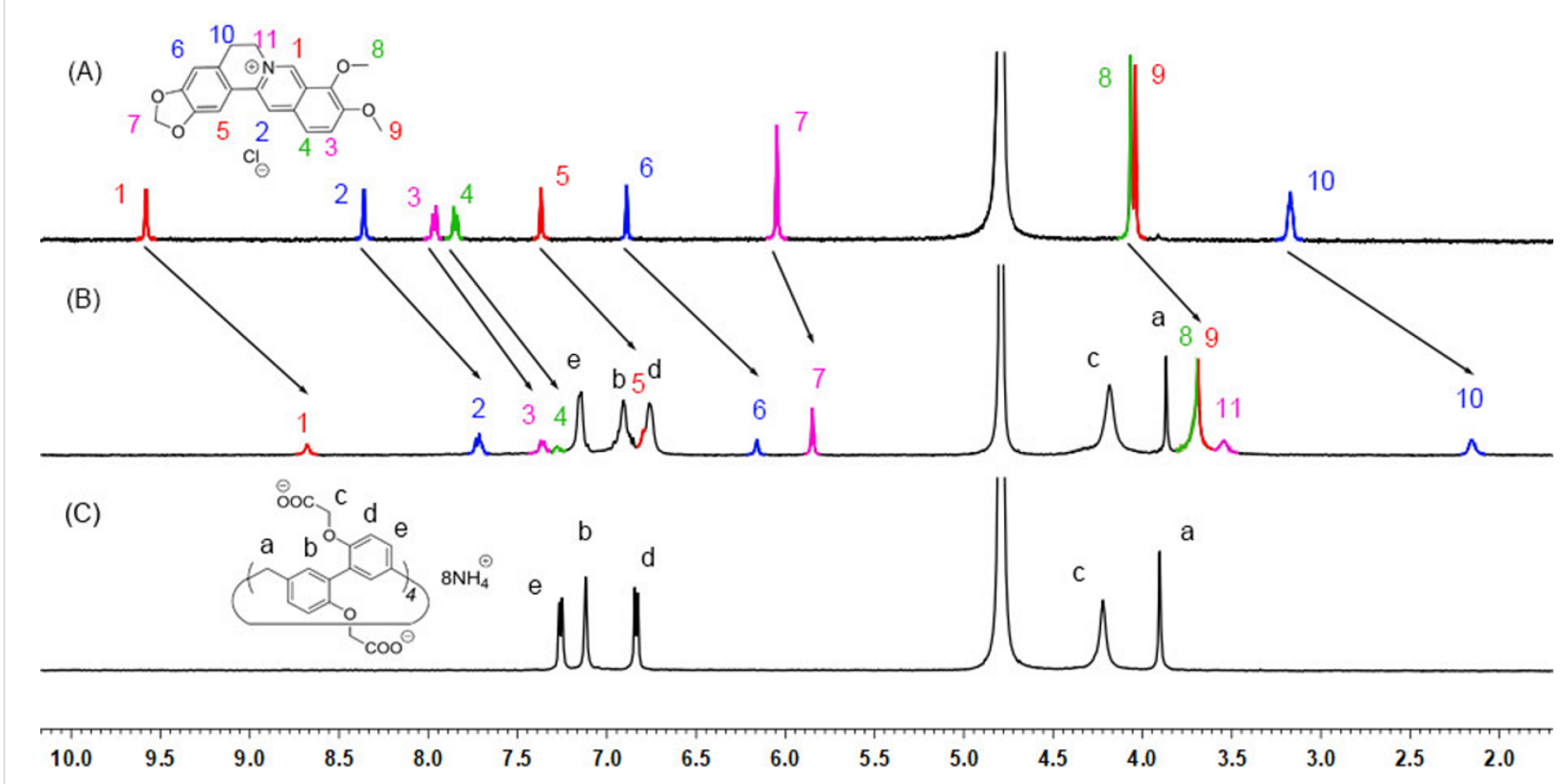

Figure 1: ${ }^{1} \mathrm{H}$ NMR spectra $(500 \mathrm{MHz}, 293 \mathrm{~K})$ of $(\mathrm{A}) \mathbf{B}(2.0 \mathrm{mM}),(\mathrm{B}) \mathbf{B}(2.0 \mathrm{mM})+2,2^{\prime}-\mathrm{CBP} 4(2.0 \mathrm{mM})$ and $(\mathrm{C}) 2,2^{\prime}-\mathrm{CBP} 4(2.0 \mathrm{mM})$ in deuterated phosphate buffer (pD 7.4). 


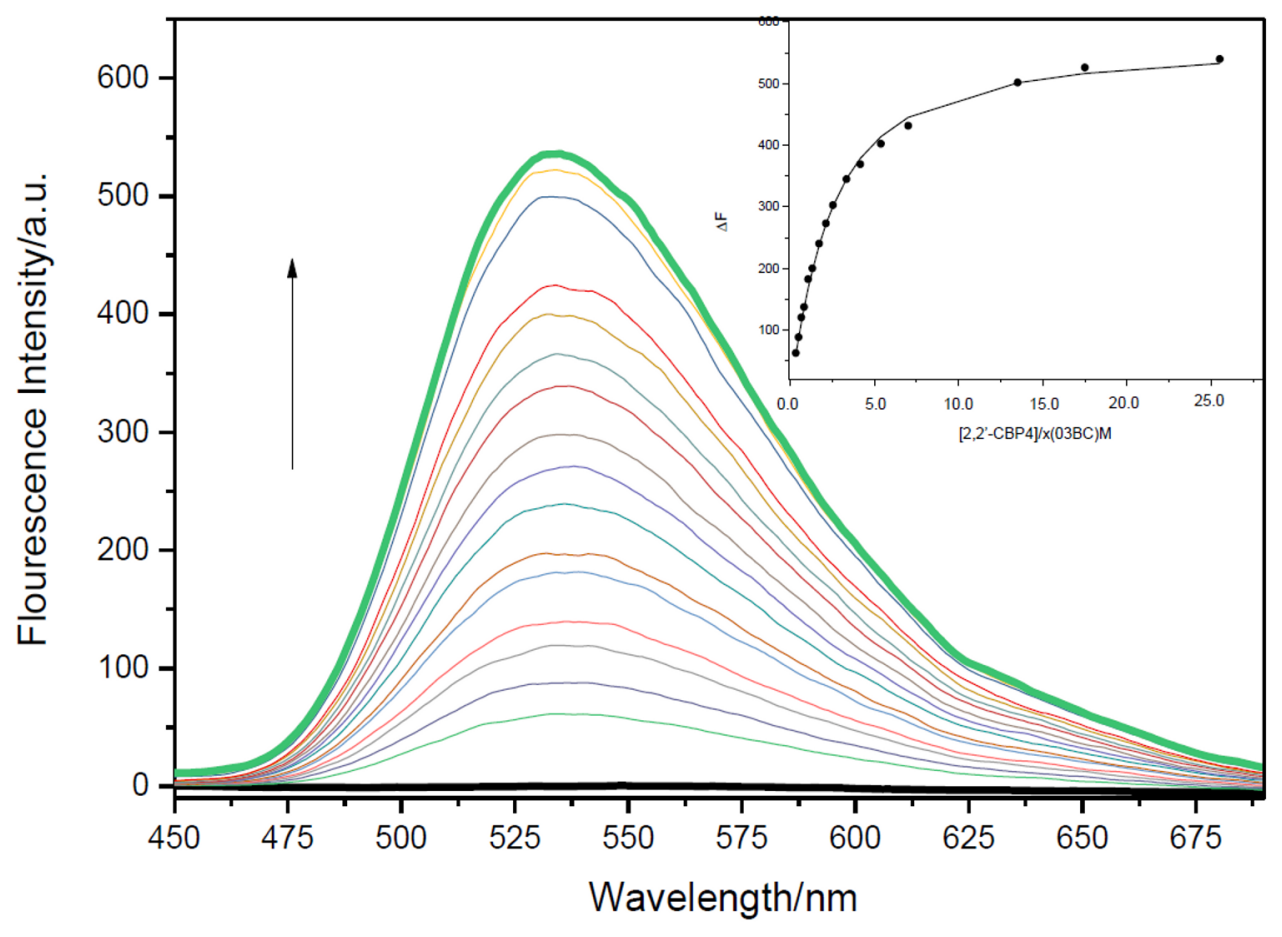

Figure 2: Fluorescence spectra of $\mathbf{P}$ in the absence and presence of 2,2'-CBP4 in aqueous phosphate buffer solution at pH 7.4 at $298 \mathrm{~K}$. The excitation wavelength is at $352.0 \mathrm{~nm}$. Inset: the nonlinear least-squares analysis to calculate the association constant using the fluorescence emission at $530 \mathrm{~nm}$.

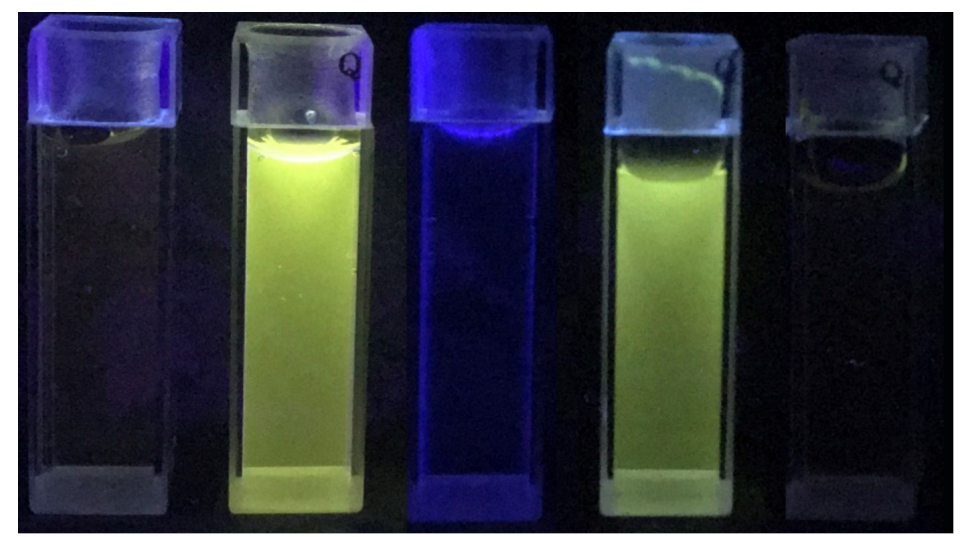

Figure 3: Visible emission observed from samples of $\mathbf{P}$ and $\mathbf{B}$ in the absence and presence of 2,2'-CBP4 under a UV lamp (365 nm). Left to right: $\mathbf{P}$, $\mathbf{P}+2,2^{\prime}-\mathrm{CBP} 4,2,2^{\prime}-\mathrm{CBP} 4, \mathbf{B}+2,2^{\prime}-\mathrm{CBP} 4$ and $\mathbf{B}$.

termined to be 1:1 by Job plot analysis (Supporting Information File 1, Figures S13 and S14). The nonlinear least-squares curvefitting method was used to analysis. For each host-guest pair, an excellent fit with an $\mathrm{R}$ value larger than 0.99 was obtained. It was found that 2,2'-CBP4 formed stable complexes with the two positively charged alkaloids, giving $K_{\mathrm{a}}$ values of $(5.87 \pm 0.24) \times 10^{5} \mathrm{M}^{-1}$ and $(2.29 \pm 0.27) \times 10^{6} \mathrm{M}^{-1}$ for $\mathbf{P}$ and B, respectively. $\pi \cdots \pi$ interactions, hydrophobic interactions and electrostatic attractions should play important roles in the association process. Although having similar structures, these two guests gave very different association constants. The substitution of 1,3-dioxole for two methoxy groups in $\mathbf{P}$, affording $\mathbf{B}$, considerably increases the $K_{\mathrm{a}}$ value of 3.9 times (Table 1). One possible reason is that the size of $\mathbf{B}$ with 1,3-dioxole, smaller than that for $\mathbf{P}$ with two methoxy groups, matches better with the cavity of 2,2'-CBP4. 
Table 1: Association constants $\left(K_{\mathrm{a}} / \mathrm{M}^{-1}\right)$ for $1: 1$ intermolecular complexation of $\mathbf{P}$ and $\mathbf{B}$ with 2,2'-CBP4 in phosphate buffer solution $(\mathrm{pH} 7.4)$ at $298 \mathrm{~K}$

\begin{tabular}{ccccc} 
host & guest & $K_{\mathrm{a}}\left[\mathrm{M}^{-1}\right]$ & Ex [nm] & Em [nm] \\
\hline 2,2'-CBP4 & P & $(5.87 \pm 0.24) \times 10^{5}$ & 352 & 533 \\
$2,2^{\prime}-\mathrm{CBP} 4$ & B & $(2.29 \pm 0.27) \times 10^{6}$ & 352 & 530
\end{tabular}

\section{Conclusion}

In summary, we have synthesized a water-soluble 2,2'biphen[4] arene, 2,2'-CBP4, for the first time and studied its complexation towards two alkaloid guests, $\mathbf{P}$ and $\mathbf{B} .{ }^{1} \mathrm{H}$ NMR and fluorescence results indicate the formation of inclusion complexes with strong stability. The association constants are in the magnitude of $10^{5}-10^{6} \mathrm{M}^{-1}$. Upon complexation with 2,2'CBP4, both alkaloid guests exhibit a significant fluorescence intensity enhancement and the intensity is strong enough to be distinguished by the naked eye. The easy accessibility, good water-solubility and nice binding properties make 2,2 '-CBP4 be applicable in the biomedical field, for example, chemical sensors, drug delivery, supramolecular amphiphiles, etc.

\section{Experimental}

2,2'-OEtBP4 was synthesized according to our previously reported method [47]. $\mathbf{P}$ and $\mathbf{B}$ were purchased from Shanghai Aladdin Bio-Chem Technology Co.,LTD. ${ }^{1} \mathrm{H}$ NMR and ${ }^{13} \mathrm{C}$ NMR spectra were recorded on a Bruker AV500 instrument. The fluorescence emission spectra were determined with a SHIMADZU RF5301 spectrometer. Deuterated phosphate buffer solutions $(20 \mathrm{mM})$ of $\mathrm{pD} 7.4$ for ${ }^{1} \mathrm{H}$ NMR experiments were prepared by mixing $\mathrm{K}_{2} \mathrm{DPO}_{4}$ deuterium oxide solution $(20 \mathrm{mM})$ and $\mathrm{KD}_{2} \mathrm{PO}_{4}$ deuterium oxide solution $(20 \mathrm{mM})$ according to the calculated volume ratios. The $\mathrm{pH} / \mathrm{pD}$ values of the buffer solutions were verified on a $\mathrm{pH}$-meter calibrated with two standard buffer solutions.

\section{Supporting Information}

\section{Supporting Information File 1}

Experimental details and the ${ }^{1} \mathrm{H}$ and ${ }^{13} \mathrm{C}$ NMR spectra of 2,2'-biphen[4] arene derivatives, additional ${ }^{1} \mathrm{H}$ NMR spectra of host-guest mixture, job plots, and the determination of the association constants.

[https://www.beilstein-journals.org/bjoc/content/ supplementary/1860-5397-14-198-S1.pdf]

\section{Acknowledgements}

This work was supported by the National Natural Science Foundation of China (21472122 and 21772118), the Shanghai
"Pujiang Program" (16PJD024), and the "Shuguang Program" of the Shanghai Education Development Foundation and Shanghai Municipal Education Commission.

\section{References}

1. Harada, A.; Hashidzume, A.; Yamaguchi, H.; Takashima, Y. Chem. Rev. 2009, 109, 5974-6023. doi:10.1021/cr9000622

2. Chen, Y.; Liu, Y. Chem. Soc. Rev. 2010, 39, 495-505. doi:10.1039/B816354P

3. Nepogodiev, S. A.; Stoddart, J. F. Chem. Rev. 1998, 98, 1959-1976. doi:10.1021/cr970049w

4. Liao, X.-J.; Chen, G.-S. Chin. Chem. Lett. 2016, 27, 583-587. doi:10.1016/j.cclet.2016.02.022

5. Walker, S.; Oun, R.; Mclnnes, F. J.; Wheate, N. J. Isr. J. Chem. 2011, 51, 616-624. doi:10.1002/ijch.201100033

6. Ma, D.; Hettiarachchi, G.; Nguyen, D.; Zhang, B.; Wittenberg, J. B.; Zavalij, P. Y.; Briken, V.; Isaacs, L. Nat. Chem. 2012, 4, 503-510. doi:10.1038/nchem.1326

7. Lazar, A. I.; Biedermann, F.; Mustafina, K. R.; Assaf, K. I.; Hennig, A.; Nau, W. M. J. Am. Chem. Soc. 2016, 138, 13022-13029. doi:10.1021/jacs.6b07655

8. Li, C.; Li, J.; Jia, X. Org. Biomol. Chem. 2009, 7, 2699-2703. doi:10.1039/b820852b

9. Chen, Y.; Huang, Z.; Zhao, H.; Xu, J.-F.; Sun, Z.; Zhang, X. ACS Appl. Mater. Interfaces 2017, 9, 8602-8608. doi:10.1021/acsami.7b01157

10. Murray, J.; Kim, K.; Ogoshi, T.; Yao, W.; Gibb, B. C. Chem. Soc. Rev. 2017, 46, 2479-2496. doi:10.1039/C7CS00095B

11.Wu, W.; Song, S.; Cui, X.; Sun, T.; Zhang, J.-X.; Ni, X.-L. Chin. Chem. Lett. 2018, 29, 95-98. doi:10.1016/j.cclet.2017.08.049

12. Gutsche, C. D. Acc. Chem. Res. 1983, 16, 161-170. doi:10.1021/ar00089a003

13. Guo, D.-S.; Uzunova, V. D.; Su, X.; Liu, Y.; Nau, W. M. Chem. Sci. 2011, 2, 1722-1734. doi:10.1039/c1sc00231g

14. Zhang, G.-W.; Li, P.-F.; Meng, Z.; Wang, H.-X.; Han, Y.; Chen, C.-F. Angew. Chem., Int. Ed. 2016, 55, 5304-5308. doi:10.1002/anie.201600911

15. Jia, F.; He, Z.; Yang, L.-P.; Pan, Z.-S.; Yi, M.; Jiang, R.-W.; Jiang, W Chem. Sci. 2015, 6, 6731-6738. doi:10.1039/C5SC03251B

16. Guo, Q.-H.; Fu, Z.-D.; Zhao, L.; Wang, M.-X. Angew. Chem., Int. Ed. 2014, 53, 13548-13552. doi:10.1002/anie.201407670

17. Guo, Q.-H.; Zhao, L.; Wang, M.-X. Angew. Chem., Int. Ed. 2015, 54, 8386-8389. doi:10.1002/anie.201503179

18. Li, C.; Xu, Q.; Li, J.; Jia, X. J. Inclusion Phenom. Macrocyclic Chem. 2009, 64, 37-42. doi:10.1007/s10847-009-9533-X

19. Megyesi, M.; Biczók, L. Chem. Phys. Lett. 2006, 424, 71-76. doi:10.1016/j.cplett.2006.04.016

20. Xiao, T.; Wang, L. Tetrahedron Lett. 2018, 59, 1172-1182. doi:10.1016/j.tetlet.2018.02.028

21. Ogoshi, T.; Kanai, S.; Fujinami, S.; Yamagishi, T.-a.; Nakamoto, Y. J. Am. Chem. Soc. 2008, 130, 5022-5023. doi:10.1021/ja711260m

22. Wanderlind, E. H.; Liz, D. G.; Gerola, A. P.; Affeldt, R. F.; Nascimento, V.; Bretanha, L. C.; Montecinos, R.; Garcia-Rio, L.; Fiedler, H. D.; Nome, F. ACS Catal. 2018, 8, 3343-3347. doi:10.1021/acscatal.8b00901

23. Yang, K.; Pei, Y.; Wen, J.; Pei, Z. Chem. Commun. 2016, 52, 9316-9326. doi:10.1039/C6CC03641D

24. Ji, X.-F.; Xia, D.-Y.; Yan, X.; Wang, H.; Huang, F.-H. Acta Polym. Sin. 2017, 9-18. 
25. Jiang, B.; Wang, W.; Zhang, Y.; Lu, Y.; Zhang, C.-W.; Yin, G.-Q.; Zhao, X.-L.; Xu, L.; Tan, H.; Li, X.; Jin, G.-X.; Yang, H.-B. Angew. Chem., Int. Ed. 2017, 56, 14438-14442. doi:10.1002/anie.201707209

26. Jie, K.; Liu, M.; Zhou, Y.; Little, M. A.; Bonakala, S.; Chong, S. Y.; Stephenson, A.; Chen, L.; Huang, F.; Cooper, A. I. J. Am. Chem. Soc. 2017, 139, 2908-2911. doi:10.1021/jacs.6b13300

27. Strutt, N. L.; Zhang, H.; Schneebeli, S. T.; Stoddart, J. F. Acc. Chem. Res. 2014, 47, 2631-2642. doi:10.1021/ar500177d

28. Wang, Y.; Ping, G.; Li, C. Chem. Commun. 2016, 52, 9858-9872. doi:10.1039/C6CC03999E

29. Li, C.; Zhao, L.; Li, J.; Ding, X.; Chen, S.; Zhang, Q.; Yu, Y.; Jia, X. Chem. Commun. 2010, 46, 9016-9018. doi:10.1039/c0cc03575k

30. Nierengarten, I.; Nothisen, M.; Sigwalt, D.; Biellmann, T.; Holler, M.; Remy, J.-S.; Nierengarten, J.-F. Chem. - Eur. J. 2013, 19 , 17552-17558. doi:10.1002/chem.201303029

31. Li, Z.-Y.; Zhang, Y.; Zhang, C.-W.; Chen, L.-J.; Wang, C.; Tan, H.; Yu, Y.; Li, X.; Yang, H.-B. J. Am. Chem. Soc. 2014, 136, 8577-8589. doi:10.1021/ja413047r

32. Si, W.; Xin, P.; Li, Z.-T.; Hou, J.-L. Acc. Chem. Res. 2015, 48, 1612-1619. doi:10.1021/acs.accounts.5b00143

33. Zhang, H.; Ma, X.; Nguyen, K. T.; Zhao, Y. ACS Nano 2013, 7, 7853-7863. doi:10.1021/nn402777x

34. Chi, X.; Ji, X.; Xia, D.; Huang, F. J. Am. Chem. Soc. 2015, 137, 1440. doi:10.1021/ja512978n

35. Cao, Y.; Li, Y.; Hu, X.-Y.; Zou, X.; Xiong, S.; Lin, C.; Wang, L. Chem. Mater. 2015, 27, 1110-1119. doi:10.1021/cm504445r

36. Li, B.; Meng, Z.; Li, Q.; Huang, X.; Kang, Z.; Dong, H.; Chen, J.; Sun, J.; Dong, Y.; Li, J.; Jia, X.; Sessler, J. L.; Meng, Q.; Li, C. Chem. Sci. 2017, 8, 4458-4464. doi:10.1039/C7SC01438D

37. Ping, G.; Wang, Y.; Shen, L.; Wang, Y.; Hu, X.; Chen, J.; Hu, B.; Cui, L.; Meng, Q.; Li, C. Chem. Commun. 2017, 53, 7381-7384. doi:10.1039/C7CC02799K

38. Yu, G.; Yu, W.; Shao, L.; Zhang, Z.; Chi, X.; Mao, Z.; Gao, C.; Huang, F. Adv. Funct. Mater. 2016, 26, 8999-9008. doi:10.1002/adfm.201601770

39. Sathiyajith, C.; Shaikh, R. R.; Han, Q.; Zhang, Y.; Meguellati, K.; Yang, Y.-W. Chem. Commun. 2017, 53, 677-696. doi:10.1039/C6CC08967D

40. Li, C.; Ma, J.; Zhao, L.; Zhang, Y.; Yu, Y.; Shu, X.; Li, J.; Jia, X. Chem. Commun. 2013, 49, 1924-1926. doi:10.1039/c3cc38622h

41. Chen, H.; Fan, J.; Hu, X.; Ma, J.; Wang, S.; Li, J.; Yu, Y.; Jia, X.; Li, C. Chem. Sci. 2015, 6, 197-202. doi:10.1039/C4SC02422B

42. Ma, J.; Deng, H.; Ma, S.; Li, J.; Jia, X.; Li, C. Chem. Commun. 2015, 51, 6621-6624. doi:10.1039/C5CC01470K

43. Zhou, J.; Yu, G.; Shao, L.; Hua, B.; Huang, F. Chem. Commun. 2015, 51, 4188-4191. doi:10.1039/C5CC00225G

44. Lande, D. N.; Rao, S. S.; Gejji, S. P. ChemPhysChem 2016, 17, 2197-2209. doi:10.1002/cphc.201600186

45. Zhou, J.; Yang, J.; Hua, B.; Shao, L.; Zhang, Z.; Yu, G. Chem. Commun. 2016, 52, 1622-1624. doi:10.1039/C5CC09088A

46. Ma, J.; Meng, Q.; Hu, X.; Li, B.; Ma, S.; Hu, B.; Li, J.; Jia, X.; Li, C. Org. Lett. 2016, 18, 5740-5743. doi:10.1021/acs.orglett.6b03005

47. Dai, L.; Ding, Z.-J.; Cui, L.; Li, J.; Jia, X.; Li, C. Chem. Commun. 2017, 53, 12096-12099. doi:10.1039/C7CC06767D

48. Flors, C.; Nonell, S. Acc. Chem. Res. 2006, 39, 293-300. doi:10.1021/ar0402863

49. Hirakawa, K.; Kawanishi, S.; Hirano, T. Chem. Res. Toxicol. 2005, 18, 1545-1552. doi:10.1021/tx0501740
50. Inbaraj, J. J.; Kukielczak, B. M.; Bilski, P.; Sandvik, S. L.; Chignell, C. F. Chem. Res. Toxicol. 2001, 14, 1529-1534. doi:10.1021/tx0155247

51. Dai, L.; Li, C.; Jia, X. China Patent CN107245028A, 2017.

\section{License and Terms}

This is an Open Access article under the terms of the Creative Commons Attribution License (http://creativecommons.org/licenses/by/4.0). Please note that the reuse, redistribution and reproduction in particular requires that the authors and source are credited.

The license is subject to the Beilstein Journal of Organic Chemistry terms and conditions:

(https://www.beilstein-journals.org/bjoc)

The definitive version of this article is the electronic one which can be found at:

doi:10.3762/bjoc. 14.198 